derisively calls "anticipation" leads us, because of our ignorance of future are unnecessary. His proposed solution is that we should spend our efforts not in anticipating what will go wrong but in creating resilience in the system.

Many of his solutions borrow from ecology. Wildavsky points out that living systems cannot anticipate specific dangers. Rather, they develop resilience, "the capacity to cope with unanticipated dangers after they become manifest, learning to bounce back" (p. 77). Other solutions are based upon neoclassical economics. Wildavsky has great faith in entrepreneurial activity, in trial-and-error risk-taking (rather than risk aversion) and in market competition, and at the heart of events, to bear opportunity costs that

his analysis is the proposition that the high-risk, entrepreneurial market system is the main reason for the rapid increase in health, safety and longevity. Competition increases wealth and distributes the discovery process throughout society, which increases both resilience and the rate of innovation. "Whether society should mainly seek to increase its ability to respond to unexpected dangers by increasing its resilience, or whether it should seek to anticipate dangers to prevent them from doing harm, is what the risk debate is about" (p. 75). Wildavsky makes a strong if polemical case for resilience over anticipation.

David L. Sills is an Executive Associate at the Social Science Research Council, 605 Third Avenue, New York, New York 10158, USA.

\section{Current questions}

\section{Peter D. Killworth}

Principles of Ocean Physics. By J.R. Apel. Academic: 1987. Pp.634. Hbk £38, \$76; pbk $£ 19, \$ 39$.

WrITING a textbook is a labour of love. The amount of material to be covered, especially in oceanography, must be daunting to any author. It is then refreshing to find that Apel has not restricted his treatment to the geographical description plus survey of geophysical fluid dynamics that is traditional in the literature. Instead, he includes coverage of acoustics, electromagnetics and optics, largely as seen from a physicist's viewpoint.

This is a praiseworthy approach, one not to be found in other textbooks, but such wide subject matter presents problems. It seems that in order to keep the text to a reasonable length, Apel has had to limit the depth of his treatment, and refer the reader as appropriate to other, more detailed sources. Sadly, that has meant that the book is not as self-contained as ideally it should have been.

There are also other flaws which detract from its effectiveness. Forward references abound, often leaping over several hundred pages, and the style of writing leaves something to be desired. Many sentences are over-long; I often had to reread whole paragraphs in order to understand them. Symbols change their meaning and acquire new dependences on other dimensions, not always with warning. Units do the same, switching from cgs to mks several times on a page, or between diagrams. For example, Fig. 9.7 is in $\mathrm{MJ}$ day ${ }^{-1} \mathrm{~m}^{-2}$, and Fig. 2.5 in W $\mathrm{m}^{-2}$; Apel provides a conversion factor, for readers with calculators, but a redrawn diagram would have been more useful. I also question the correctness of placing units after a symbolic algebraic equation.
The unit $\mathrm{W}\left(\mathrm{m}^{2} \mathrm{Km}^{-1}\right)^{-1}$, found on p. 141, although intended to help the reader, must surely do the opposite.

The index, a cornerstone of any textbook, is worse than useless. "Density of seawater" has one reference! "Debye absorption" leads the reader to "something like Debye absorption (see Chapter 8)"; after searching therein, a reference to "dipole moment (see Section 4.1)" is found - but dipole moment is not mentioned in Section 4.1. Should the student forget the definition of, say, zenith angle, the index will not help him. I collected a full page of omissions of this nature, and there were many more.

Despite the lengthy errata, many mistakes remain. For example, equation 7.14 defines the modulus of a vector to be a complex number; the left-hand-side of equation 8.55 is real, the right-hand-side imaginary; and the Ekman number as defined in Appendix 5 is identically unity.

Geophysical fluid dynamics is made easier because certain terms are small and can be omitted ('scaling'). Almost no mention of this is made, making the treatment hard to follow. The placing of material is odd, too: steady motions are dealt with in a chapter entitled "Waves and Tides", and quasigeostrophic motion appears to be defined as a small perturbation to an eastward flow. It is hard to find out from the text how large typical values of quantities are: how does the reader interpret a 'large dipole moment' of 1.84 debye without some feel for the size of an ordinary one?

It grieves me not to be able to be more enthusiastic about this book. I applaud the author's motives, but the result is confusing and littered with errors. It will be of some use to those seeking a feel for physical oceanography, but new graduate students should look elsewhere.

Peter D. Killworth is a Principal Scientific Officer at the Deacon Laboratory, Institute of Oceanographic Sciences, Wormley, Godalming, Surrey GU8 $5 U B, U K$

\section{Treatment of the future}

\section{David Weatherall}

Human Gene Therapy. By Eve K. Nichols. Harvard University Press:1988. Hbk \$22.95, £18.50; pbk \$9.95, £7.95.

IN A FIELD that is moving so rapidly that anything other than overnight success is unthinkable, human gene therapy seems to have been just around the corner for an embarrassingly long time. But having been bitten once by a premature attempt, clinicians will want to ensure that several prerequisites are fulfilled before their patients are subjected again to somatic gene therapy - that is, the transfer of genes into cells other than those of the germ line in order to cure an inherited disease.

First, to counsel prospective patients or their families it must be possible to give an accurate account of the clinical course of the illness and its response to more conventional therapy; genetic diseases vary in their severity, and even when the underlying molecular lesions are known the reasons for their clinical heterogeneity often remain unexplained. Second, we must be able to find the appropriate gene and define its main regulatory regions. Third, we have to identify and isolate the appropriate target cells and develop efficient and safe vectors with which to transfect them. Finally, there must be clear evidence from animal experiments that the inserted gene will function adequately, that the recipient cell population will have a reasonably long life-span, and that the gene we have transferred will produce no deleterious effects in its new home. Human Gene Therapy shows just how far we are from meeting these requirements.

In October 1986, the Institute of Medicine of the National Academy of Sciences held a conference on gene therapy and the organizers invited Eve Nichols to write an account of the meeting for non-experts. She has succeeded remarkably well in this daunting task, and has set out both the scientific background and ethical problems with great clarity.

After introductory chapters that describe how recombinant DNA technology has been applied to the study of human disease, the remainder of the book is devoted to an explanation of the use of retroviral vectors for gene transfer. It concludes with a short section on ethical and economic issues and how, in the United States, federal regulation of programmes for gene therapy is being organized. Eve Nichols has the unusual knack of being able to simplify complex matters without compromising scientific accuracy. She has 